\title{
New Onset Heart Failure after Right Ventricular Pacing in Patients with Normal Left Ventricular Function
}

\author{
Fawad Qadir ${ }^{1}$, Muhammad Shahid ${ }^{1}$, Hadi Yousuf Saeed ${ }^{1}$, Muhammad Tahir Mohyudin ${ }^{2}$, Abu Bakar Ali \\ Saad $^{3}$, Zahid Iqbal ${ }^{4}$ \\ ${ }^{1}$ Senior Registrar, Department of Cardiology, CPE Institute of Cardiology, Multan, Pakistan \\ ${ }^{2}$ Associate Professor, Department of Cardiology, CPE Institute of Cardiology, Multan, Pakistan \\ ${ }^{3}$ Assistant Professor, Department of Cardiology, CPE Institute of Cardiology, Multan, Pakistan \\ ${ }^{4}$ Senior Registrar, Department of Cardiology, DG Khan Medical College/Hospital DG Khan, Pakistan
}

\begin{abstract}
A B S TR ACT
Background: Cardiac pacing is the best optional treatment for cardiac rhythm disturbances such as cardiac arrhythmias, high grade atrioventricular (AV) block and heart failure (HF). Right ventricular apical (RVA) pacing in patients with normal left ventricular heart, may stimulate $\mathrm{HF}$ and cardiomyopathy. The objective of this study was to dete rmine the frequency of new-onset heart failure after right ventricular apical pacing in patients having normal left ventricular (LV) function.

Material and Methods: This prospective study was conducted from March 2017 to January 2019 in Chaudhry Pervaiz Elahi (CPE) Institute of Cardiology, Multan Pakistan. Adult patients $(n=50)$ who fulfilled the American College of Cardiology (ACC) guidelines for permanent pacemaker (PPM) insertion and with normal LV function were included in this study. Pacemaker was implanted in all patients under local anesthesia. All patients were followed up for six months to determine the occurrence of heart failure. 2-D echocardiography was done to determine heart failure at follow up in pacemaker clinic.

Results: Mean age of the study participants was $50.53 \pm 6.75$ years with male predominance. Mean pre-implantation ejection fraction (EF\%) was $55.4 \pm 4.2 \%$. Main reason of PPM insertion was third degree AV block followed by right bundle branch block (RBBB). Incidence of HF was $4 \%$ at 06 months' follow-up. Mortality occurred only in 1 (2\%) patient. Conclusions: Right ventricular pacing is associated with risk of new onset heart failure in long term follow-up. In the present study, HF developed in $4 \%$ patients in a follow-up period of six months.

Key words: Heart failure, Permanent pacemaker, Right ventricular pacing.

$\begin{array}{ll}\text { Authors' Contribution: } & \text { Correspondence: } \\ { }^{1} \text { Conception; Literature } \quad \text { research; } & \text { HadiYousuf Saeed } \\ \text { manuscript design and drafting; }{ }^{2,3} \text { Critical } & \text { Email:doc.cpeic@gmail.com }\end{array}$

Article info:

Received: July 14, 2019

analysis and manuscript review; ${ }^{4-7}$ Data

Email:doc.cpeic@gmail.com

Accepted: December 22, 2020

analysis; Manuscript Editing.
\end{abstract}

Cite this article. Qadir F, Shahid M, Saeed HY, Mohyudin MT, Saad ABA, Iqbal Z. New Onset Heart Failure after Right Ventricular Pacing in Patients with Normal Left Ventricular Function. J Islamabad Med Dental Coll. 2021; 10(1):51-55. Doi: 10.35787/jimdc.v10i1.378

Funding Source: Nil Conflict of Interest: Nil

\section{Introduction}

Cardiac pacing is the best optional treatment for cardiac rhythm disturbances such as cardiac arrhythmias, high grade AV block and heart failure. ${ }^{1-}$
${ }^{3}$ Since decades, right ventricular apex is a suitable site for the conventional pacing. This is because endocardial pacing leads are stable and safe at RV 
apical site. Patients with high degree AV block require a cardiac pacemaker. Worldwide, every year 750,000 new cardiac pacemakers are being implanted with one quarter of them in the USA itself. $^{4}$

In normal left ventricular heart, right ventricular apical pacing may increase symptoms of heart failure and cardiomyopathy. ${ }^{5}$ Clinical and experimental data shows RVA pacing may cause development of left ventricular systolic dysfunction. ${ }^{6}$ In a short-term study, Sá et al. showed that there were non-significant effects in patients with normal LV function, ${ }^{7}$ even though, the development of LV dysfunction mechanism is still not understood. This might be caused by age, underlying disease spread and stimulation related issues. $^{8}$

The aim of the present study was to find out the clinical and echocardiographic effects of onset heart failure in right ventricular apex pacing in patients treated for high degree AV block with normal LV function.

\section{Material and Methods}

This prospective study comprising 50 patients was conducted from March 2017 to January 2019 in CPE Institute of Cardiology, Multan Pakistan. Adult patients who presented with complete AV block, type II second-degree AV block and sinus node disease with first-degree AV block and PR interval $>200$ milli-seconds were included. These patients had normal LV function and also fulfilled the American College of Cardiology/ American Heart Association guidelines for permanent pace-maker insertion. Patients having $\mathrm{EF}<50 \%$, or heart failure at the time of inclusion were excluded. Written consent was taken from all the study participants. Approval from Ethics Committee of CPE Institute of Cardiology was taken as well.
Pacemaker was implanted in all patients under local anesthesia. The leads were passed through left or right subclavian vein and were fixed the in right atrial appendage/septum, while the second lead was positioned in the right ventricular apex/septum. The RV lead was fixed by rotating it anti-clockwise using 3D stylet. The procedure was done in cardiac catheterization laboratory, under fluoroscopy guidance. Narrow QRS complex was used as conformation.

After pacemaker insertion, 12-lead ECG was done in each patient to program pacemaker at 150 to 180 milli-second on discharge. The paced QRS duration measured at each lead pacing spike manually in all 12 ECG leads.

All patients were followed up for six months to determine the incidence of heart failure. 2-D echocardiography was done to determine heart failure at follow up in pacemaker clinic. Only two patients were lost to follow-up and in their place two new patients were added.

Data was organized and analyzed using SPSS v 23 software. Qualitative variables like gender, onset of heart failure, diabetes and hypertension were presented as frequency and percentages, while the quantitative variables like age and ejection fraction were presented as mean and standard deviation (SD).

\section{Results}

Mean age of the study participants was $50.53 \pm 6.75$ years with a male predominance (78\% males and $22 \%$ females). About 29 (58\%) patients were hypertensive, and 18 (34\%) patients were diabetic. Mean pre-implantation ejection fraction (EF\%) was $55.4 \pm 4.2 \%$. Main reason of PPM insertion was third degree AV block followed by RBBB. Incidence of HF was $4 \%$ at six months' follow-up. Mortality occurred only in $1(2 \%)$ patient (Table I). 


\begin{tabular}{|l|l|c|}
\hline \multicolumn{2}{|c|}{$\begin{array}{c}\text { Table I: Clinicopathological characteristics of study } \\
\text { participants (n=50) }\end{array}$} \\
\hline Mean Age (years) & \multicolumn{2}{|c|}{$50.53 \pm 6.75$} \\
\hline \multirow{2}{*}{ Gender n (\%) } & Male & $39(78)$ \\
\cline { 2 - 3 } & Female & $11(22)$ \\
\hline Diabetes n (\%) & \multicolumn{1}{|c|}{ 29 (58) } \\
\hline Hypertension n (\%) & \multicolumn{1}{|c|}{$5 \pm 4.2$} \\
\hline Baseline EF (Mean) & LBBB & $03(6)$ \\
\hline \multirow{4}{*}{$\begin{array}{l}\text { Reason of insertion n } \\
\text { (\%) }\end{array}$} & $\begin{array}{l}\text { AVBB block } \\
\text { second degree }\end{array}$ & $04(8)$ \\
\cline { 2 - 3 } & $\begin{array}{l}\text { AV block third } \\
\text { degree }\end{array}$ & $29(58)$ \\
\hline \multirow{2}{*}{$\begin{array}{l}\text { New-onset Heart } \\
\text { Failure n (\%) }\end{array}$} & Yes & $2(4)$ \\
\cline { 2 - 3 } & No & $48(96)$ \\
\hline \multirow{2}{*}{ Mortality n (\%) } & Yes & $49(98)$ \\
\cline { 2 - 3 } & No & \\
\hline
\end{tabular}

\section{Discussion}

Since the second half of the $20^{\text {th }}$ century, right ventricular apex pacing has been selected for the pacemaker implantation because of stability and ease of implantation. ${ }^{9}$ Even though, PPM stimulation is more often extensively related to ventricular dysfunction. ${ }^{10}$

In the present study, among 50 patients who were randomly selected over a period of 22 months in the $\mathrm{RV}$ apex pacing, two patients had ejection fraction of less than $40 \%$.

Many studies have assessed the pacemaker-induced ventricular dysfunction without previous history of heart failure. In a single center study conducted on 257 pacemaker implanted patients with normal LV ejection fraction, about $20 \%$ of patients with RV apex pacing developed pacing-induced cardiomyopathy (a drop in LV ejection fraction of $\geq 15 \%$ from the baseline). The LV ejection fraction dropped to $\geq 20 \%$ at a mean follow-up time of 3 years. ${ }^{11}$ In Pacing to Avoid Cardiac Enlargement (PACE) trial, 86 patients of PPM were included and followed for 1 year. They reported HF in 9\% patients after RV pacing and in only $1 \%$ patients in biventricular pacing group. ${ }^{12}$

Ebert et al. conducted a study to determine the reasons of PPM insertion on LV function. ${ }^{13}$ The researchers divided the study patients into "SA node group" and "AV block group". They did not find any significant effect of predisposing factors on LV function in a mean follow-up of 44 months. In their study, only $6 \%$ patients developed heart failure. ${ }^{13}$

Another study by Sa et al. reported that conventional RV pacing is a risk factor of worsening of 6-minute walk test, LV functional class, increased BNP levels, and prolongation of QRS in a long-term follow-up. ${ }^{14}$

Some previous studies reported that right ventricular apex pacing should be avoided due to the chances of left ventricular dyssynchrony. ${ }^{15,16}$ An abnormal generation and activation of electrical sequence leads to elevation of mitral valve insufficiency, ventricular hypertrophy and decreased ventricular ejection fraction. ${ }^{17,18}$ Other option of inserting leads is to select the right ventricular septal pacing rather than RV apex, that has been documented to reduce the risk of LV dyssynchrony. ${ }^{19,20}$ Right ventricular septal pacing decreases the paced QRS duration on ECG and reduces the dyssynchony on 2-D echocardiography. ${ }^{21}$ A study conducted by Domenichini et al. compared the septal and apical pacing and followed the patients for 4 years. The authors did not find any significant difference in the risk of LV dysfunction and concluded that both apical and septal pacing positions have similar impact on LV function. ${ }^{22}$

There are certain limitations of this study. Firstly, a sample size of only 50 patients is not enough to draw significant conclusions. Secondly, the study population was not homogenous and indications of pacemaker insertion were not the same for each 
patient. Therefore, the underlying etiology may also have a different impact on RV function.

\section{Conclusion}

In the present study new-onset HF developed in $4 \%$ patients after right ventricular apical pacing in a follow-up period of six months. RV pacing is associated with risk of new onset heart failure in long term follow-up.

\section{References}

1. Kusumoto FM, Schoenfeld $\mathrm{MH}$, Barrett $\mathrm{C}$, Edgerton JR, Ellenbogen KA, Gold MR, et al. 2018 ACC/AHA/HRS guideline on the evaluation and management of patients with bradycardia and cardiac conduction delay: A report of the American College of Cardiology/American Heart Association Task Force on clinical practice guidelines and the Heart Rhythm Society. J Am Coll Cardiol. 2019; 74(7): e51-e156. Doi: 10.1016/j.jacc.2018.10.044.

2. Cevik C, Nugent K, Perez-Verdia A, Fish RD. Prophylactic implantation of cardioverter defibrillators in idiopathic nonischemic cardiomyopathy for the primary prevention of death: a narrative review. Clin Cardiol. 2010; 33(5): 254-60. Doi: 10.1002/clc.20757.

3. Yang B, Cheng Y, Zhang D-E. The Indications and Notice of Installation Temporary Pacemaker or Permanent Pacemaker. Medicine and Biopharmaceutical. 2016; 161-8. Doi: 10.1142/9789814719810_0019.

4. Mond HG, Proclemer A. The 11th world survey of cardiac pacing and implantable cardioverterdefibrillators: calendar year 2009--a World Society of Arrhythmia's project. Pacing Clin Electrophysiol. 2011; 34(8): 1013-27. Doi: 10.1111/j.15408159.2011.03150.x.

5. Ooka J, Tanaka H, Hatani Y, Hatazawa K, Matsuzoe H, Shimoura $\mathrm{H}$, et al. Risk Stratification of Future Left Ventricular Dysfunction for Patients with Indications for Right Ventricular Pacing due to Bradycardia. Int Heart J. 2017; 58(5): 724-30. Doi: 10.1536/ihj.16-415.

6. Freudenberger RS, Wilson AC, Lawrence-Nelson J, Hare JM, Kostis JB. Permanent pacing is a risk factor for the development of heart failure. Am J Cardiol. 2005; 95(5): 671-4. Doi: 10.1016/j.amjcard.2004.10.049.

7. Crevelari ES, Silva KRD, Albertini CMM, Vieira MLC, Martinelli Filho M, Costa R. Efficacy, Safety, and Performance of Isolated Left vs. Right Ventricular
Pacing in Patients with Bradyarrhythmias: A Randomized Controlled Trial. Arq Bras Cardiol. 2019; 112(4): 410-21. Doi: 10.5935/abc.20180275.

8. Tops LF, Schalij MJ, Bax JJ. The effects of right ventricular apical pacing on ventricular function and dyssynchrony implications for therapy. J Am Coll Cardiol. 2009; 54(9): 764-76. Doi: 10.1016/j.jacc.2009.06.006.

9. Furman S, Robinson $G$. The use of an intracardiac pacemaker in the correction of total heart block. Surg Forum. 1958; 9: 245-8. PMID: 13635360.

10. Sweeney MO, Hellkamp AS. Heart failure during cardiac pacing. Circulation. 2006; 113(17): 2082-8. Doi: 10.1161/CIRCULATIONAHA.105.608356.

11. Khurshid S, Epstein AE, Verdino RJ, Lin D, Goldberg LR, Marchlinski FE, et al. Incidence and predictors of right ventricular pacing-induced cardiomyopathy. Heart Rhythm. 2014; 11(9): 1619-25. Doi: 10.1016/j.hrthm.2014.05.040.

12. Yu C-M, Chan JY-S, Zhang Q, Omar R, Yip GW-K, Hussin $A$, et al. Biventricular pacing in patients with bradycardia and normal ejection fraction. N Engl J Med. 2009; 361(22): 2123-34. Doi: 10.1056/NEJMoa0907555.

13. Ebert $M$, Jander $N$, Minners J, Blum $T$, Doering $M$, Bollmann $A$, et al. Long-Term Impact of Right Ventricular Pacing on Left Ventricular Systolic Function in Pacemaker Recipients with Preserved Ejection Fraction: Results from a Large Single -Center Registry. J Am Heart Assoc. 2016; 5(7): e003485. Doi: 10.1161/JAHA.116.003485.

14. Sá LABd, Rassi S, Batista MAL. Is conventional cardiac pacing harmful in patients with normal ventricular function? Arq Bras Cardiol. 2013; 101(6): 545-53. Doi: 10.5935/abc.20130205.

15. Thambo JB, Bordachar P, Garrigue S, Lafitte $S$, Sanders $P$, Reuter $S$, et al. Detrimental ventricular remodeling in patients with congenital complete heart block and chronic right ventricular apical pacing. Circulation. 2004; 110(25): 3766-72. Doi: 10.1161/01.CIR.0000150336.86033.8D.

16. Tse HF, Lau CP. Long-term effect of right ventricular pacing on myocardial perfusion and function. J Am Coll Cardiol. 1997; 29(4): 744-9. Doi: 10.1016/s07351097(96)00586-4.

17. Prinzen FW, Augustijn $\mathrm{CH}$, Arts $\mathrm{T}$, Allessie MA, Reneman RS. Redistribution of myocardial fiber strain and blood flow by asynchronous activation. Am J Physiol. 1990; 259(2 Pt 2):H300-8. Doi: 10.1152/ajpheart.1990.259.2.H300.

18. Nahlawi M, Waligora M, Spies SM, Bonow RO, Kadish $\mathrm{AH}$, Goldberger JJ. Left ventricular function during and after right ventricular pacing. J Am Coll Cardiol. 2004; 44(9): 1883-8. Doi: 10.1016/j.jacc.2004.06.074. 
19. Yusu S, Mera H, Hoshida K, Miyakoshi M, Miwa Y, Tsukada $T$, et al. Selective site pacing from the right ventricular mid-septum. Follow-up of lead performance and procedure technique. Int Heart J. 2012; 53(2): 113-6. Doi: 10.1536/ihj.53.113.

20. Flevari $P$, Leftheriotis $D$, Fountoulaki K, Panou F, Rigopoulos AG, Paraskevaidis I, et al. Long-term nonoutflow septal versus apical right ventricular pacing: relation to left ventricular dyssynchrony. Pacing Clin Electrophysiol. 2009; 32(3): 354-62. Doi: 10.1111/j.1540-8159.2008.02244.x.
21. Cano O, Osca J, Sancho-Tello MJ, Sanchez JM, Ortiz V, Castro JE, et al. Comparison of effectiveness of right ventricular septal pacing versus right ventricular apical pacing. Am J Cardiol. 2010; 105(10): 1426-32. Doi: 10.1016/j.amjcard.2010.01.004.

22. Domenichini G, Sunthorn H, Fleury E, Foulkes $H$, Stettler C, Burri H. Pacing of the interventricular septum versus the right ventricular apex: a prospective, randomized study. Eur J Intern Med. 2012; 23(7): 621-7. Doi: 10.1016/j.ejim.2012.03.012. 